\title{
Thermodynamic and Spectrophotometric Studies of Electron Donor-Acceptor Complexation Between Loratadine and Chloranilic Acid
}

\author{
Kenneth C Ofokansi ${ }^{1}$ and Philip F Uzor ${ }^{2^{*}}$ \\ ${ }^{1}$ Department of Pharmaceutics, Faculty of Pharmaceutical Sciences, ${ }^{2}$ Department of Pharmaceutical and Medicinal Chemistry, \\ University of Nigeria, Nsukka 41001, Nigeria
}

*For correspondence: E-mail: philuzor4u@yahoo.com; Tel: +234-803-7008 294

Received: 10 May 2012

Revised accepted: 29 January 2013

\begin{abstract}
Purpose: To developing a simple, rapid and reliable analytical method for loratadine based on charge transfer complexation with chloranilic acid.

Methods: The complex between loratadine and the complexing agent, chloranilic acid, was formed by mixing appropriate volumes of their solutions in non-aqueous media. Some features of the formed complex, such as molar ratio of the reaction and effect of time, were determined spectrophotometrically. Thermodynamic parameters were determined as well, the method was utilized in the assay of the drug in both bulk and tablet dosage forms.

Results: The complex showed a wavelength of maximum absorption $\left(\lambda_{\max }\right)$ at $527 \mathrm{~nm}\left(\lambda_{\max }\right.$ of loratadine alone was $440 \mathrm{~nm})$. Beer's law was obeyed in the concentration range of $3.2-28.8 \mathrm{mg} \%\left(r^{2}=0.9997\right)$. The stoichiometry of the complex was 2:1 (loratadine: chloranilic acid) and the complex was stable for over $60 \mathrm{~min}$. Thermodynamic results show that as temperature changed from 30 to $70{ }^{\circ} \mathrm{C}$, enthalpy change $(\Delta H)$ was steady at $-0.254 \mathrm{kcal}^{\mathrm{mol}} \mathrm{I}^{1}$ while the free energy $(\Delta \mathrm{G})$ changed from -3.904 to -4.450 kcal.mol ${ }^{1}$. The complex appeared to be more stable at the slightly elevated temperature of $50{ }^{\circ} \mathrm{C}$ with a value of $757.14 \mathrm{~mol}^{1}$. Analysis of the drug in both bulk and dosage forms showed good accuracy and precision with recovery ranging from $99.98 \pm 1.00$ to $100.94 \pm 2.39 \%$.

Conclusion: Charge transfer complexation method with chloranilic acid was successfully developed for the simple, rapid and accurate determination of loratadine.
\end{abstract}

Keywords: Charge transfer, Complexation, Loratadine, Spectrophotometry, Electron donor-acceptor, Chloranilic acid.

Tropical Journal of Pharmaceutical Research is indexed by Science Citation Index (SciSearch), Scopus, International Pharmaceutical Abstract, Chemical Abstracts, Embase, Index Copernicus, EBSCO, African Index Medicus, JournalSeek, Journal Citation Reports/Science Edition, Directory of Open Access Journals (DOAJ), African Journal Online, Bioline International, Open-J-Gate and Pharmacy Abstracts

\section{INTRODUCTION}

Drug substances and drug products are routinely analyzed for impurities and related substances and for assay of active pharmaceutical ingredient (API) content to ensure efficacy and safety of the pharmaceutical product. One of the simplest methods of drug analysis is the formation of charge transfer complexes between the drug acting as electron donor and various electron deficient reagents acting as electron acceptors [1]. Molecular interactions between electron donors and acceptors are generally associated with the formation of intensely colored chargetransfer complexes, which absorb radiation in the visible region where many of the common excipients used in the formulation of the drug products do not absorb light. A variety of electron donating compounds have been reported to yield charge-transfer complexes leading to their utility 
in the development of simple and convenient colorimetric methods [1-3].

Loratadine $\{$ (Ethyl-4-(8-chloro-5,6-dihydro-11 Hbenzo $(5,6)$ cyclohepta $(1,2-b)$ pyridine-1piperidine carboxylate is a second generation, non-sedating, long-acting antihistamine which is employed in the symptomatic relief of allergies such as hay fever, urticaria and seasonal allergic rhinitis and it elicits this effect by selective and peripheral antagonistic action on histamine -1 receptors [4]. Several methods have been reported for the determination of loratadine in pharmaceutical preparations including spectrophotometry [5], polarography [6], densitometry [7], capillary electrophoresis [8], gas chromatography [9], high performance liquid chromatography [10], liquid chromatographytandem mass spectrophotometry [11], spectrofluorimetric and potentiometric methods [12]. Many of these methods require expensive equipment and/or are time-consuming [12]; hence the need to develop a method that is simple, sensitive and fast, yet reliable and reproductive. Since there is a basic centre in the chemical structure of loratadine (Fig 1a) which is a potential electron donating site, charge transfer complexation with an electron acceptor, as a colorimetric method, is considered such a simple method for fast and reliable assay of the drug. The present study was aimed at investigating this complexation reaction using chloranilic acid (CAA, Fig 1b) as a $\pi$-acceptor, with the expectation of developing a new analytical method for loratadine. The thermodynamic parameters of the formed complex were determined as well.<smiles>CCOC(=O)N1CCC(=C2c3ccc(Cl)cc3CCc3cccnc32)CC1</smiles>

(a)<smiles>O=C1C(O)=C(Cl)C(=O)C(O)=C1Cl</smiles>

(b)

Fig 1: Structure of (a) loratadine and (b) chloranilic acid (CAA)

\section{EXPERIMENTAL}

\section{Materials}

The following materials were procured from their local suppliers: loratadine tablet dosage forms, Loratyn $10^{\circledR}$ (Hovid, Malaysia) and Lotin $^{\circledR}$ (Medreich Ltd, India). Other materials used were 1, 4-dioxan (Merck, Germany), chloroform (May and Baker, England). Loratadine bulk powder was a kind donation by Juhel Nig Ltd. All other reagents and solvents were of analytical grade and were used as such. All laboratory reagents were freshly prepared. Distilled water was collected from an all-glass still.

\section{Preparation of standard solutions}

A stock solution of CAA with a concentration of $3.34 \times 10^{-3} \mathrm{M}$ was prepared by dissolving $0.069 \mathrm{~g}$ of accurately weighed CAA powder in 1, 4-dioxan and making up to $100 \mathrm{~mL}$ with the same solvent. Similarly a stock solution of loratadine in chloroform was prepared by accurately weighing $0.064 \mathrm{~g}$ of loratadine into a $100 \mathrm{~mL}$ volumetric flask and making up to volume with chloroform to provide a $1.67 \times 10^{-3} \mathrm{M}$ solution. Other concentrations were similarly prepared or diluted from the stock with the appropriate solvent.

\section{Absorption spectra of loratadine and chloranilic acid}

Loratadine stock solution $(2 \mathrm{~mL})$ was mixed with $3 \mathrm{~mL}$ of chloroform and the solution scanned in a spectrophotometer (UNICO 2102 PC, USA) over a wavelength range of $400-700 \mathrm{~nm}$ to determine its wavelength of maximum absorption $\left(\lambda_{\max }\right)$ against a blank made up of $5 \mathrm{~mL}$ of chloroform. Similar procedure was followed in the scanning of the solution of CAA in 1,4-dioxan over the same wavelength range.

\section{Determination of absorption spectrum of loratadine-chloranilic acid complex}

CAA stock solution $(2 \mathrm{~mL})$ was mixed with $2 \mathrm{~mL}$ of loratadine stock solution in a flask and the contents were left at room temperature for $1 \mathrm{~h}$. A colour developed and the complex formed was scanned against the blank of equal volumes of dioxan and chloroform over a wavelength range of $400-700 \mathrm{~nm}$ using the spectrophotometer as above.

\section{Evaluation of chromogen concentration effect on complex formation}

To determine the optimum concentration of the chromogen (CAA) to form the complex, a fixed 
volume of loratadine stock solution $(2 \mathrm{~mL})$ was added to various volumes $(0.5,1.0,1.5 \ldots 2.5 \mathrm{~mL})$ of CAA stock solution, and the absorbance was monitored to determine the chromogen concentration which yielded maximum complexation with loratadine.

\section{Construction of standard plot for loratadine- chloranilic acid complex}

Serial concentrations of $0.2,0.4 \ldots \ldots .1 .8 \mathrm{~mL}$ of loratadine stock solution in $0.2 \mathrm{~mL}$ steps were transferred to different test tubes. Sufficient volume of chloroform was added to bring the volume in each test tube to $2 \mathrm{~mL}$. Then $2 \mathrm{~mL}$ of CAA stock solution was added to each of the test tubes to afford the final concentrations of loratadine ranging from $8.35 \times 10^{-5} \mathrm{M}$ to 7.52 $\times 10^{-4} \mathrm{M}$. The contents were mixed and left at room temperature for $1 \mathrm{~h}$. The absorbance of each sample was determined at $527 \mathrm{~nm}$ against a blank made up of equal volumes of chloroform and 1, 4-dioxan.

\section{Evaluation of time - absorbance relationship}

A time - absorbance relationship was established for the complex to determine the time required for the complex to develop fully. Equal volumes (2 $\mathrm{mL}$ each) of the two stock solutions were mixed and the absorbance measured at various time intervals from zero to $180 \mathrm{~min}$ at $527 \mathrm{~nm}$.

\section{Determination of stoichiometry of the complex}

The Job's method of continuous variation was employed for the determination of the stoichiometry of the reaction [13]. Equimolar concentrations $\left(3.34 \times 10^{-3} \mathrm{M}\right)$ of solutions of loratadine and CAA were used for the experiment. A series of $5 \mathrm{~mL}$ volumes of mixtures of the above solutions comprising complementary proportions of the two solutions corresponding to $0.5: 4.5 ; 1: 4 ; \ldots 4.5: 0.5$ of loratadine: CAA solutions were transferred into different test tubes and the complex formed for each reaction mixture was allowed to stand for 1 $\mathrm{h}$ at room temperature before analysis at 527 $\mathrm{nm}$. A blank solution consisting of 1, 4-dioxan and chloroform was used.

\section{Determination of stability constant, molar absorptivity and other thermodynamic parameters}

Serial volumes of the stock solution of loratadine ranging from 0.4 to $2.4 \mathrm{~mL}$ in $0.4 \mathrm{~mL}$ steps were transferred to different test tubes. The solutions were diluted to $3 \mathrm{~mL}$ with chloroform and $1 \mathrm{~mL}$ of the stock solution of CAA was added to each test tube. The contents were capped and mixed by gentle shaking. The test tubes were allowed to stand for $1 \mathrm{~h}$ at room temperature $\left(30^{\circ} \mathrm{C}\right)$, and absorbance measurements were taken with a spectrophotometer at $527 \mathrm{~nm}$ against a blank of chloroform and dioxan. Further analyses of the reaction mixtures were done at elevated temperatures of 50 and $70{ }^{\circ} \mathrm{C}$.

\section{Assay procedure for loratadine in tablet dosage form and in bulk form}

One hundred loratadine tablets were ground and thoroughly mixed by trituration in a mortar and an amount equivalent to $0.064 \mathrm{~g}$ of active drug was accurately weighed. This was dissolved in a 100 $\mathrm{mL}$ flask with $70 \mathrm{~mL}$ of chloroform and shaken for $30 \mathrm{~min}$ to extract the active drug. The suspension was filtered to remove the excipients and the latter washed with $20 \mathrm{~mL}$ of chloroform. The filtrate was thereafter made up to $100 \mathrm{ml}$ with chloroform to provide a theoretical concentration of $1.67 \times 10^{-3} \mathrm{M}$ solution of loratadine. Serial volumes of $0.2,0.4 \ldots \ldots .2 .0 \mathrm{~mL}$ of loratadine solution in $0.2 \mathrm{~mL}$ steps of the solution were transferred into different test tubes. Sufficient chloroform was added in each case to bring the volumes to $2.5 \mathrm{~mL}$. Then $2.5 \mathrm{~mL}$ of $3.34 \times 10^{-3} \mathrm{M}$ CAA solution was added in each case to bring the final volume to $5 \mathrm{~mL}$. The contents were mixed and left for $1 \mathrm{~h}$ at room temperature after which their absorbances were determined at 527 $\mathrm{nm}$ against a blank of chloroform and dioxan. The procedure was carried out in four replicates. Percentage recoveries of loratadine from the dosage form were calculated by reference to the Beer's plot. For the bulk loratadine sample, the experiment above was repeated except that there was no prior extraction from the tablet dosage form.

\section{Statistical analysis}

The data were expressed as mean \pm standard deviation ( $S D, n=4)$. Statistical significance of difference between brands of the drug was determined by Student's't' test followed by oneway analysis of variance (ANOVA) and $p<0.05$ was considered as statistically significant. Data were analyzed with SPPS 16.0 software.

\section{RESULTS}

\section{Absorption spectra}

Chloranilic acid (CAA) solution in 1, 4-dioxan gave a yellow colour with an absorption maximum $\left(\lambda_{\max }\right)$ at $430 \mathrm{~nm}$ while loratadine had $\lambda_{\max }$ at $440 \mathrm{~nm}$. On addition of a solution of 
loratadine in chloroform to CAA solution, the colour changed to purple and a bathochromic shift to a longer wavelength ( $\lambda_{\max }$ of $527 \mathrm{~nm}$ ) was obtained at room temperature (Fig. 2). Measurements were carried out at $527 \mathrm{~nm}$. The different variables were studied and optimized.

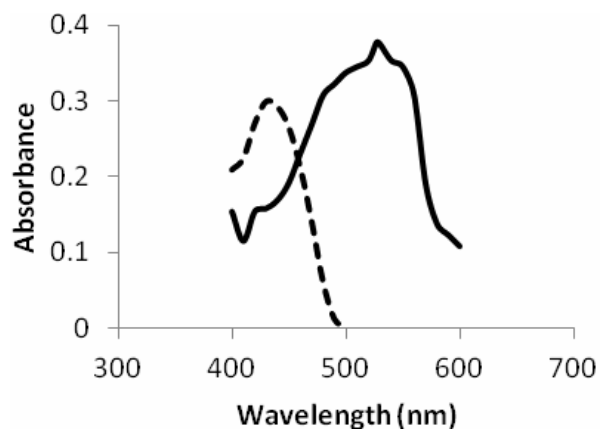

Fig 2: Absorption spectra of chloranilic acid (.....) and loratadine-chloranilic acid complex $(\longrightarrow$

\section{Effect of chromogen concentration on complex formation}

A mixture of 1, 4-dioxan and chloroform was found to be an ideal solvent for the formation of the complex. The optimum volume of CAA was found to be $2.0 \mathrm{~mL}$ which was taken at the highest absorbance reading of 0.235 . This volume was used throughout the whole experiment for the formation of the complex.

\section{Effect of time on complex formation}

The optimum reaction time was determined from the absorbance readings and by monitoring the color development at room temperature $(30 \pm 2$ $\left.{ }^{\circ} \mathrm{C}\right)$. The absorbance of the complex increased gradually from zero to $60 \mathrm{~min}$ and remained fairly constant up till 90 min after the commencement of the experiment. After this period there was a gradual decline in absorbance. Absorbance reading ranged between 0.220 and 0.240 (Fig. 3). Also complete colour development was attained at $60 \mathrm{~min}$ and the colour of the complex remained fairly stable until $90 \mathrm{~min}$. Absorbance measurements were therefore taken 60 min after mixing the reagents.

\section{Beer's plot for loratadine-chloranilic acid complex}

The regression equation for the plot of absorbance of complex formed against loratadine concentration was derived using the least-square method as:

$\mathrm{A}_{527 \mathrm{~nm}}=0.011 \mathrm{x}+0.0018$

where $x$ is the concentration $(\mathrm{mg} \%)$ of loratadine. At $527 \mathrm{~nm}$, Beer's law was obeyed by the complex; the plot was linear with very small intercept. A good correlation coefficient $\left(r^{2}=\right.$
0.9997) was obtained between the absorbance and the concentration over the entire range studied (3.2-28.8 $\mathrm{mg} \%$ of loratadine).

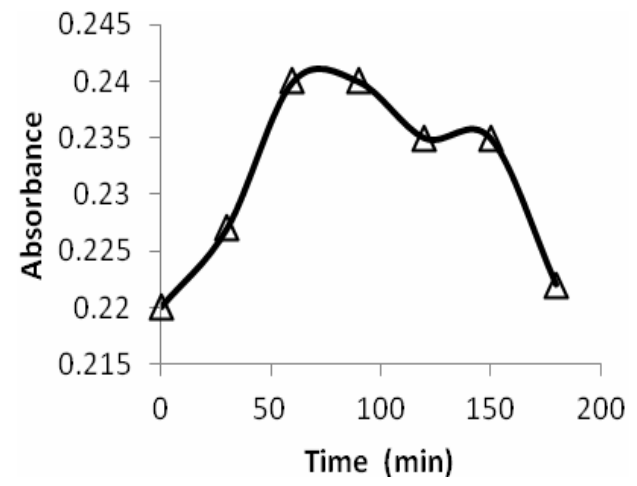

Fig 3: Time absorbance relationship for the loratadinechloranilic acid complex at room temperature

Job's plot for loratadine-chloranilic acid complex

The stoichiometry of the complex, according to Job's plot, was found to be 2:1 (loratadine: CAA, Fig 4).

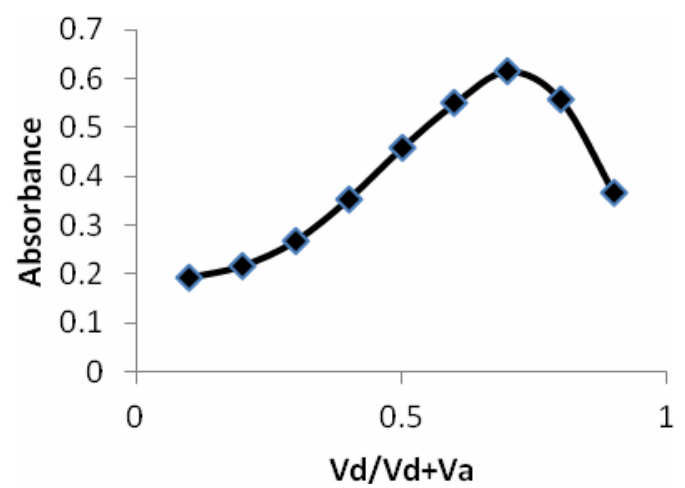

Figure 4: Job's plot of continuous variation for loratadine-chloranilic acid complex Key: $\mathrm{Vd}=$ volume of laratadine; $\mathrm{Va}=$ volume of $\mathrm{CAA}$

Stability constant, molar absorptivity and other thermodynamic parameters

The molar absorptivity $(\varepsilon)$, association constant and other thermodynamic parameters for the loratadine-CAA complex were evaluated using the Benesi-Hildebrand equation, Eq 2 [14].

$\frac{\left[A_{0}\right]}{A_{i}^{[A=D]}}=\frac{1}{E_{i}^{[A \cdot D]}}+$

$\frac{1}{\left[E_{i}^{[A D D}\right]\left[k_{C}^{\left[A D D_{1}\right]}\right.} \times \frac{1}{\left[D_{0}\right]}$

where $\left[D_{0}\right]$ and $\left[A_{\circ}\right]$ are initial concentrations of the reactants, $A_{\lambda}^{[A: D]}$ is the absorbance of the complex at $527 \mathrm{~nm}, E_{\lambda}^{[A: D]}$ is the molar absorptivity of the complex at $527 \mathrm{~nm}$, and $\mathrm{K}_{\mathrm{c}}^{[\mathrm{A}: D]}$ is the stability constant. The intercepts and slopes of the regression lines from a plot of 
$\frac{\left[A_{0}\right]}{A_{0}^{[A: D]}}$ against $\frac{1}{\left[D_{0}\right]}$ were used to calculate the values of $E_{\lambda}^{[A: D]}$ and $K_{c}^{[A: D]}$ respectively. The data obtained for the stability constants $\left(K_{c}^{[A: D]}\right)$ at different temperatures were further utilized to calculate the standard enthalpy change $\left(\Delta H^{\circ}\right)$ using Eq 3 [15].

$\log K_{D}^{[A: D]}=\frac{\Delta H^{0}}{2.303 R T}+$ constant

where $\mathrm{R}$ is the gas constant. Also Gibb's free energy change $\left(\Delta G^{\circ}\right)$ and the entropy change $\left(\Delta S^{\circ}\right)$ were calculated respectively from Eq. (4) and Eq. (5), and the results presented in Table 1. $\Delta G^{\circ}=-\operatorname{RTh} K_{\sigma}^{[A: D]}$

$\Delta G^{\circ}=\Delta H^{\circ}-T \Delta S^{\circ}$.

\section{Recovery experiment}

The applicability of the proposed method for the analysis of loratadine was assessed using the drug in both bulk and tablet dosage forms and the recoveries obtained were $100.94 \pm 2.39$, $100.53 \pm 1.74$ and $99.98 \pm 1.00 \%(n=4)$ for the bulk sample of loratadine, Loratyn-10 ${ }^{\circledR}$ and Lotin ${ }^{\circledR}$ brands, respectively. The differences in the values of the recoveries were not statistically significant $(p>0.05)$.

\section{DISCUSSION}

The change of the yellow color of CAA in 1, 4dioxan to a purple colour upon reaction with loratadine and the bathochromic shift were taken as indication of charge transfer complex formation between the drug acting as n-donor and chloranilic acid as a $\pi$-acceptor followed by the formation of radical anion according to the proposed mechanism (Scheme 1) [16-17].

$\mathrm{D}+\mathrm{A}$
(Donor) $\leftrightarrow \underset{\text { (Acceptor) }}{[\mathrm{D}-\mathrm{A}]} \leftrightarrow \leftrightarrow \begin{gathered}\mathrm{D}^{+}+\mathrm{A}^{-} \\ \begin{array}{c}\text { Donor-acceptor } \\ \text { Radical ions }\end{array}\end{gathered}$

Scheme 1: Equation of donor- acceptor reactions

The effect of time on the complex formation suggests that the complex was stable for over 60 min allowing enough time for the analysis to take place. The high regression coefficient of the Beer's plot for the complex showed the linearity of the relationship between absorbance and concentration. Conformity with Beer's law was an indication that spectrophotometric analysis of electron donor-acceptor formation could be employed in the quantitative analysis of loratadine. The result of the molar ratio of reaction suggests that two moles of loratadine formed the complex with one mole of CAA. The formed complex between loratadine and CAA was more stable at slightly elevated temperatures than at higher and lower temperatures as suggested by the stability constant values. Loratadine-chloranilic acid complex was more stable with increasing temperature up to a temperature of $50{ }^{\circ} \mathrm{C}$. This was also visually evident by increase in the intensity of the purple coloration of the formed complex with increasing temperature. Beyond this critical temperature of $50{ }^{\circ} \mathrm{C}$, a gradual decrease in intensity of purple coloration was observed, an indication of gradual dissociation as the temperature was raised beyond the critical temperauture that favours complex formation. The negative value of the free energy indicates the spontaneity of the reaction while the negative value of the entropy change $(\Delta S)$ indicates a decrease in the degree of freedom of the molecules upon complexation [18]. The negative value of the enthalpy change $(\Delta \mathrm{H})$ indicate that the complexation reaction was exothermic. Thus, high temperatures might have favoured the dissociation of the complex. This explains why high temperatures led to decrease in the molar absorptivity values of the complex. Overall, the thermodynamic parameters suggest that the complex was more stable at slightly elevated temperatures than at high temperatures. Recovery experiments showed high quantitative recoveries with low standard deviation by the proposed assay method. The recovery values obtained for both the pure sample of the drug and the tablet dosage forms were not significantly different indicating the reproducibility and practical application of the method. The

Table 1: Thermodynamic parameters of the charge-transfer complex between loratadine and chloranilic acid

\begin{tabular}{|c|c|c|c|c|c|}
\hline $\begin{array}{l}\text { Temp } \\
\text { (K) }\end{array}$ & $\begin{array}{l}\mathrm{K}_{\mathrm{C}}^{[\mathrm{A}: \mathrm{D}]} \\
\left(\mathrm{mol}^{-1}\right)\end{array}$ & $\begin{array}{l}\text { Molar } \\
\text { absorptivity }\end{array}$ & $\begin{array}{l}\Delta \mathrm{G}^{\mathrm{o}} \\
\left({\left.\mathrm{kcal} . \mathrm{mol}^{-1}\right)}\right.\end{array}$ & $\begin{array}{l}\Delta \mathrm{H}^{\mathrm{O}} \\
\left({\left.\mathrm{kcal} . \mathrm{mol}^{-1}\right)}^{-1}\right.\end{array}$ & $\begin{array}{c}\Delta \mathrm{S}^{\circ} \\
\left(\mathrm{kcal}^{-1} \cdot \mathrm{mol}^{-1}\right)\end{array}$ \\
\hline 303 & 961.925811 .096 & -4.137 & 6.9117 & 0.0365 & \\
\hline 323 & 1305.827 & $714.704-4.606$ & “ & \multicolumn{2}{|c|}{0.0357} \\
\hline 343 & 3865.392 & $483.653-5.631$ & “ & \multicolumn{2}{|c|}{0.0366} \\
\hline
\end{tabular}


proposed method gave true values according to the label claims and this suggests the accuracy of the method. The results were not affected by the presence of excipients in the tablets since the excipients were removed before analysis and could not absorb at $527 \mathrm{~nm}$. The proposed method is simple, fast, accurate and precise.

\section{CONCLUSION}

The reaction between loratadine and chloranilic acid was spontaneous and yielded a complex which was quite stable for over one hour, giving enough time for the analysis. This complexation reaction was successfully employed in the assay of loratadine in both bulk and in tablet dosage forms with good precision and accuracy. It is recommended that the accuracy and precision of the proposed method be validated using larger number of dosage forms of the drug and comparing inter-laboratory results.

\section{ACKNOWLEDGEMENT}

The authors are grateful to Juhel Nig Ltd, Enugu, Nigeria for the kind donation of a pure sample of loratadine.

\section{REFERENCES}

1. Khaled E. Spectrophotometric determination of terfenadine in pharmaceutical preparations by charge-transfer reactions. Talanta 2008; 75(5): 1167-1174.

2. El-Zaria ME. Spectrophotometric study of the charge transfer complexation of some porphyrin derivatives as electron donors with tetracyanoethylene. Spect Chim Acta A 2008, 69(1): 216-221.

3. Ofokansi KC, Adikwu MU. Qualitative detection of some electron donor drugs on thin layer plates. chloranilic acid as the locating reagent in nonaqueous media. J Pharm Allied Sci 2004; 2: 226232.

4. Katzung, BG. Basic \& Clinical Pharmacology. $9^{\text {th }}$ ed. USA: The McGraw-Hill Companies; 2004; pp 482-495.

5. María JC, Héctor CG. Determination of loratadine and pseudoephedrine sulfate in pharmaceuticals based on non-linear second-order spectrophotometric data generated by a $\mathrm{pH}$-gradient flow injection technique and artificial neural networks. Anal Bioanal Chem 2007; 389: 2217-2223.

6. Ghoneim MM Mabrouk MM Hassanein AM, Tawfik $A$. Polarographic behaviour of loratadine and its direct determination in pharmaceutical formulation and human plasma by cathodic adsorptive stripping voltammetry. J Pharm Biomed Anal 2001; 25: 933937.

7. Indrayanto G, Darmawan L, Widjaja S, Noorrizka G. Densitometric determination of loratadine in pharmaceutical preparations and validation of the method. J Planar Chromatogr Modern TLC 1999; 12: 261-268.

8. Fernandez $H$, Ruperez FJ, Barbas C. Capillary electrophoresis determination of loratadine and related impurities. J Pharm Biomed Anal 2003; 31: 499-506.

9. Johnson R, Christensen J, Lin CC. GC method of loratadine determination. $J$ Chromatogr Biomed Appl 1994; 657: 125-134.

10. Rupe'rez FJ, Ferna'ndez H, Barbas C. LC determination of loratadine and related impurities. J Pharm Biomed Anal 2002; 29: 35-41.

11. Sutherland FCW, de Jager $A D$, Badenhorst $D$, Scanes $T$, Hundt HKL, Swart KJ, Hundt AF. Sensitive liquid chromatography-tandem mass spectrometry method for the determination of loratadine and its major active metabolite descarboethoxyloratadine in human plasma. J Chromatogr A 2001; 914 (1):37-43.

12. Mashhadizadeh MH, Hadjiakhoondi A, Ahmadaghaei S. A novel PVC membrane sensor for determination of loratadine in pharmaceutical compounds and blood serum. J Iran Chem Soc 2011; 8(3): 687-693.

13. Job R. Advanced Physicochemical Experiments. London: Pitman; 1964; $p 54$.

14. Benesi HA, Hildebrand JH. Ultraviolet absorption bands of iodine and aromatic hydrocarbon. J Am Chem Soc 1949; 70: 2032-2036.

15. Attama AA, Nnamani PO, Agbo AN. Development of alternative assay technique for cephalexin by charge transfer interaction of the donor: acceptor type with chloranilic acid. Chinese Pharm J 2006; 58:11-18.

16. Salem H. Analytical study for the charge-transfer complexes of gabapentin. Afr J Pharm Pharmacol 2008; 2 (7): 136-144.

17. Basavaiah K, Charan VS. The use of chloranilic acid for the spectrophotometric determination of three antihistamines. Turk J Chem 2002; 26: 653-661.

18. Obonga WO, Omeje EO, Uzor PF, Ugwu MO. Spectrophotometric determination and thermodynamic parameters of charge transfer complexation between stavudine and chloranilic acid. Trop J Pharm Res 2011; 10: 817-823. 